\title{
Três olhares de além-mar: o museu como espaço de divulgação da ciência
}

\author{
Three views from overseas: the museum as a setting \\ for educational outreach in the sciences
}

\author{
Michel Van Praet \\ Diretor do Departamento \\ das Galerias do \\ Museu Nacional de História \\ Natural de Paris \\ Jean Davallon e \\ Daniel Jacobi \\ Professores do Laboratório \\ Cultura e Comunicação da \\ Universidade de Avignon. \\ Entrevistas concedidas a: \\ Luciana Sepúlveda \\ Koptcke e Luisa Massarani \\ Pesquisadoras do Museu da \\ Vida, Casa de Oswaldo Cruz, \\ Fiocruz \\ Av. Brasil, 4365 \\ 21040-900 Rio de Janeiro - RJ \\ Brasil \\ lsk@coc.fiocruz.bre \\ lumassa@coc.fiocruz.br
}

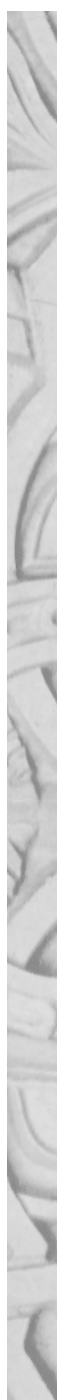

VAN PRAET, M.; DAVALLON, J. e JACOBI, D.: Três olhares de além-mar: o museu como espaço de divulgação da ciência. (Entrevistas concedidas a Luciana Sepúlveda Koptcke e Luisa Massarani).

História, Ciências, Saúde - Manguinhos, v. 12 (suplemento), p. 349-64, 2005.

Em sua primeira visita ao Brasil, em 2001, os professores Michel Van Praet, Jean Davallon e Daniel Jacobi, pesquisadores e profissionais do campo museal francês, discutiram a natureza complexa da experiência museal. Michel Van Praet salienta a particularidade dos museus de história natural e avalia o trabalho que realisou à frente do projeto de renovação da Grande Galeria da Evolução do Museu Nacional de História Natural, inaugurada, em 1994, em Paris. Jean Davallon discute a contribuição da semiótica e da teoria da recepção para analisar como a exposição comunica e como se dá a construção de sentido em seu interior. Daniel Jacobi define algumas características da divulgação das ciências nos museus e aponta dificuldades para a sua realização.

PALAVRAS-CHAVE: museus, ciência, educação não formal, divulgação científica, teoria da comunicação, museologia.

VAN PRAET, M.; DAVALLON, J. and JACOBI, D.: Three views from overseas: the museum as a setting for educational outreach in the sciences (Interviews by Luciana Sepúlveda Koptcke and Luisa Massarani).

História, Ciências, Saúde - Manguinhos, v. 12 (supplement), p. 349-64, 2005.

During their first visit to Brazil, in 2001, Michel Van Praet, Jean Davallon, and Daniel Jacobi - French researchers in the field of museology-discussed the complex nature of the museum experience. Professor Van Praet underscores the unique character of natural history museums and offers an evaluation of his work as head of the restoration project at Paris's Grande Gallery of Evolution, inaugurated in 1994. Professor Davallon discusses the contribution of semiotics and reception theory in analyzing how an exhibit communicates and how meaning is constructed within it. Dr. Jacobi defines some characteristics of the dissemination of science at museums and points to problems encountered in achieving this end.

KEYWORDS: museums, science, informal education, educational outreach in the sciences, communication theory, museology. 
$\mathrm{E}$ m 2001 o Museu da Vida realizou, em parceria com o Museu de Astronomia e Ciências Afins (Mast), o Encontro sobre a Pesquisa em Educação, Comunicação e Divulgação em Museus (Epecodim) reunindo, no Rio de Janeiro, profissionais e pesquisadores de diversas instituições do Brasil e da América Latina.

Entre os palestrantes convidados encontravam-se os professores Michel Van Praet, Jean Davallon e Daniel Jacobi, responsáveis pela criação, em 1993, do primeiro curso de Diploma de Estudos Aprofundados (DEA) ${ }^{1}$ e de doutorado em Museologia, na universidade francesa.

O curso, intitulado DEA de Museologia: Públicos, Exposições, Instituições, era fruto da parceria entre o Muséum National d'Histoire Naturelle (MNHN) de Paris, o Conservatório de Artes e Ofícios e a Universidade de Sainte Étienne, Jean Monnet. ${ }^{2}$

A instituição museu estruturou-se na interface das funções de pesquisa, conservação, ensino e extensão, com peso, importância e grau de articulação variáveis, segundo cada instituição.

Desse modo, o Diploma francês, anteriormente mencionado, assim como a realização de um Encontro (Epecodim 2001) inteiramente consagrado às questões da educação não formal, da comunicação e da divulgação da ciência nos museus, no Brasil, sugerem que o campo museal vem reafirmando a importância das suas funções de educação e extensão. Ademais, o museu vem se colocando como produtor de conhecimentos particulares que extrapolam as disciplinase os temas sugeridos por suas coleções, conhecimentos estes oriundos da análise do próprio fenômeno museal na sociedade. ${ }^{3}$

A educação não formal nos museus, o funcionamento comunicacional das exposições e o potencial para popularizar a ciência são questões aqui abordadas pelos pesquisadores e professores franceses.

\footnotetext{
1 O Diploma de Estudos Aprofundados (DEA) permite o ingresso no doutorado na França. Corresponderia ao mestrado brasileiro, embora esta equivalência seja discutida atualmente na universidade brasileira.

2 O curso em questão foi, posteriormente, cindido em dois: o DEA de Museologia Científica (do Museu Nacional de História Natural de Paris) e o DEA de Museologia de Sainte Étienne, que abrange outras áreas além da científica.

${ }^{3}$ Entre as primeiras iniciativas de formação profissional no campo dos museus, consta aquela que foi proposta com a criação da Escola do Louvre, no século XIX, em que se procurava garantir uma formação técnica especializada para os responsáveis pelos museus. A formação então dispensada aos alunos da Escola do Louvre sinalizava que, além da atividade de pesquisa em campos de saber como a antropologia, a arqueologia, a etnografia, a história natural, a geologia, a história da arte, a história nacional, realizada nos museus, outras competências precisavam ser desenvolvidas - como a organização do acervo, a restauração dos objetos, a organização dos espaços expositivos. Um conhecimento para assegurar a realização das missões da instituição então definidas, nem sempre de forma explícita, como a produção de certo tipo de conhecimento, a transformação de objetos e idéias em patrimônio nacional, a difusão deste patrimônio como valor compartilhado.
} 


\section{Entrevista com Michel Van Praet}

Michel Van Praet ocupou os cargos de chairman do comitê francês do Conselho Internacional de Museus (ICOM - sigla em inglês) e de diretor das galerias de Anatomia e Paleontologia no MNHN de Paris. Entre 1986 e 1994, foi o responsável pela renovação da Grande Galeria da Evolução. Desenvolve pesquisas sobre a história dos museus de história natural, história das estações marítimas, além de pesquisas sobre zoologia na Associação Francesa para o Avanço das Ciências, sendo responsável pelo DEA de Museologia do MNHN.

Afirma-se que a década de 1990 foi marcada por mudanças significativas na filosofia e na forma de apresentação dos museus e centros de cultura científica. O senhor concorda com esta posição? Se concorda, em que consistem tais mudanças?

As apresentações dos museus foram várias vezes modificadas em função de mudanças de grandes conceitos científicos e filosóficos, como a adoção da classificação de Lineu no século XVIII, ou a crescente percepção dos processos de transformação nas realidades estudadas pela ciência no século XIX; portanto, convém não considerar tal mudança como algo novo no nosso meio. Mais que científica, a mudança é provavelmente maior na atenção crescente dada a nossos visitantes, às suas expectativas, a seus conhecimentos, diga-se mesmo às suas competências, já que se trata de interagir com eles.

A partir da década de 1990, também se observa uma tendência ao uso de equipamentos 'interativos' nos museus e centros de cultura científica. Como o senhor define a interatividade nos museus? Quais são, a seu ver, seus limites?

A interatividade, se ela se resume ao fato de apertar um botão, como se pode deduzir às vezes em certas exposições, é muito pouco. A interatividade a ser desenvolvida é a que está relacionada à especificidade de nossos ambientes. Museus são ambientes conviviais, de saída em grupo (amigos, familiares, escolares, turistas). ${ }^{4}$ É preciso fazer tudo para desenvolver a intermediação entre os funcionários do museu e os visitantes, mas também dos visitantes entre si.

Isto determina uma 'museografia de sociabilidade', que joga com a repetição de um mesmo tema sobre suportes cenográficos diferentes para compelir cada membro do grupo a encontrar o suporte

\footnotetext{
${ }^{4} \mathrm{O}$ autor refere-se a saídas em comum - "Ces sont des lieux de sortie en commun" - o que não evidencia, em nosso idioma, o sentido pretendido. Desta forma, sugeriu-se o termo 'convivial' e a caracterização da saída como 'saída em grupo'. (N.E.)
} 
de sua escolha e, então, retornar ao grupo para dividir a experiência que acabou de viver e descobrir, assim que os outros membros encontraram outros ângulos do mesmo assunto. É um prazer imenso ver uma criança iniciar sua avó no manejo de um computador, e a avó debater sobre o que acabou de apreciar em uma vitrine, bem próxima, dedicada ao mesmo tema.

A definição de um projeto museológico para uma instituição museal ou a concepção museográfica de uma exposição estabelecem os primeiros esforços de mediação entre os saberes, os objetos, as idéias, as culturas e os visitantes das instituições museais. O senhor concorda com esta visão ampliada da mediação dentro dos museus? Quais são, no momento, os principais pressupostos e tendências da mediação nos museus e centros de cultura científica, técnica e industrial?

Concordo com essa visão. É uma primeira etapa de mediação, tendo em vista a concepção de exposições, a renovação ou a criação de um museu. As principais tendências e os pressupostos mereceriam uma longa explanação. Em poucas palavras, é possível discernir duas. Primeira : procurar não difundir um saber enciclopédico, como foi de fato o objetivo social de construção do honnête homme e do 'cidadão' desde a época do Iluminismo, mas definir os caminhos de formação do cidadão contemporâneo face à quantidade, diversidade e especificidade de saberes impossíveis de conhecer em sua totalidade. Segunda: permitir ao maior número de pessoas ter contato com a ciência e com a explosão dos conhecimentos científicos para ajudálas a dominar certos pontos de referência, a compreender os modos de organização e trabalho da comunidade científica e lhes permitir conhecer a diversidade das possibilidades de comunicação que as ajudarão nas suas escolhas cidadãs.

Os museus são fontes de inovação pedagógica? Como o senhor avalia a evolução dos intercâmbios entre a educação formal e os museus?

Acho melhor evitar o termo pedagógico quando se fala de exposição ou de ação no ambiente museal. A relação com a instituição escolar deveria se desenvolver em termos de parceria, cada um assumindo as suas diferenças.

No Brasil, a proposta de classificação dos museus em "primeira, segunda e terceira geração" obteve grande popularidade entre os pesquisadores. Como o senhor vêe esta classificação?

Ela demonstra bem que houve uma evolução, mas receio que esta classificação seja às vezes redutora. Ocorreu uma grande mudança entre as 'coleções de curiosidades' e os museus do século XVIII, mas tanto uns quanto outros realçaram conceitos de exaustividade do saber e das coleções. Houve, em seguida, uma segunda revolução, com a passagem destes 'museus-bibliotecas de 
objetos' à procura da exaustividade, quando surgiu a 'exposição', no fim do século XIX. Estas exposições, com uma seleção de objetos tratando de um único tema, nos levaram a uma certa autonomia da exposição em relação ao museu, mas isto faz mais de 120 anos. A criação das exposições no fim do século XIX foi acompanhada de uma dissociação do espaço do museu entre as funções de 'reserva' e de 'exposição'. Isto contribuiu e permitiu que fosse realmente levada em conta a comunicação com os visitantes, mas os privou da percepção da diversidade das atividades dos museus (pesquisa, coleta, conservação). Devemos fazê-los redescobrir a cada visita que isto é impossível.

O senhor afirmou que: "É junto da história das ciências que se deve procurar os inspiradores do gesto museal, mas é igualmente junto de uma sociologia da organização da pesquisa que se deve examinar as lógicas da pedagogia museal". O senhor crê que os museus e centros de cultura científica, técnica e industrial constituem, no momento, um "campo autônomo", no sentido empregado por Bourdieu? Como o senhor avalia a evolução das equipes profissionais nessas instituições?

Penso que não caberia utilizar o termo "campo autônomo", mesmo considerando que a exposição tem especificidades no campo das mídias. A evolução muito lenta das equipes profissionais e de sua profissionalização nos museus e centros de cultura científica confirma aliás, em parte, o peso da comunidade científica, que tem dificuldades de aceitar a profissionalização da mediação das ciências, compartilhando com essa comunidade o espaço do museu.

Os museus de história natural têm especificidades com relação a outros museus? Quais são elas?

As especificidades dos museus de história natural ocorrem em dois campos. Primeiro : eles têm um papel essencial na compreensão da natureza e das relações do homem com a natureza, no tempo e no espaço. Eles têm, portanto, responsabilidades essenciais face à conservação do patrimônio natural. Segundo: eles trabalham com espécimes vivos, ou que o foram; seu papel na distinção entre 'real' e 'virtual' é essencial, particularmente hoje, quando a educação para tal distinção é ainda balbuciante.

A renovação da Galeria de Zoologia propôs o desafio de "conservar o espirito do lugar, ainda que criando um museu moderno". O senhor participou ativamente dessa renovação. Quais foram as dificuldades mais importantes nesse processo? Como o senhor avalia o projeto, sete anos após a inauguração? Ele atraiu novas gerações de visitantes?

"Conservar o espírito do lugar" dizia respeito, no caso da Galeria de Zoologia, à preservação da excepcional arquitetura metálica do edifício inaugurado em 1889; mas "conservar o espírito do lu- 
gar" incluía também elementos museológicos ainda mais importantes, e isto teve de ser bem explicado aos arquitetos e cenógrafos.

A galeria, tendo sido o lugar de conservação das coleções nacionais de zoologia, e a pesquisa do museu, centrada sobre a coleta e o estudo das coleções, deveriam estar presentes na cenografia, ainda mais levando-se em conta a riqueza dos milhões de espécimes científicos naturalizados. Um dos objetivos museográficos era partir das coleções para estruturar tanto o propósito científico quanto a experiência emocional oferecida aos visitantes. Tratava-se, portanto, de utilizar as novas tecnologias como auxiliares didáticos à interpretação dos conteúdos, e não como os suportes atrativos principais, contrariamente ao que era a tendência em muitos museus concebidos na época. Em relação a esta noção de 'espírito do lugar', convinha igualmente mostrar que o museu é, depois de mais de três séculos, um lugar de pesquisa e debate científico. A nossa maior dificuldade foi organizar a infinidade de temas propostos pelos colegas do museu e suprimir alguns entre as centenas de temas apresentados.

Sete anos após a inauguração, a escolha por uma museografia apoiada sobre a riqueza das coleções se revelou sábia. O desenvolvimento contínuo do virtual na sociedade contemporânea só fez aumentar o interesse das coleções para oferecer emoções originais aos visitantes. A apresentação, por exemplo, de centenas de espécies desde o fim do século XVIII, espécies hoje ameaçadas de extinção ou até mesmo desaparecidas de nosso planeta, tem um impacto extremamente forte para os visitantes e dá à visita da Galeria um caráter excepcional. No que concerne à vinda de novos freqüentadores, a implantação de estudos de avaliação do público do museu desde o fim da década de 1980 permitiu estudar o impacto da abertura da Galeria da Evolução, em 1994, e acompanhar, em seguida, a transformação desse público. Em relação aos objetivos de crescimento deste, foi possível atrair mais turistas do interior do país e do estrangeiro, se bem que em termos de democratização o impacto tenha sido bem menor. Pode-se, ao mesmo tempo, comemorar a duplicação de assalariados e operários entre os freqüentadores e lastimar que eles só representem $10 \%$ de nossos visitantes regulares.

Que conselhos ou sugestões o senhor daria aos colegas brasileiros, se eles quiserem empreender um projeto semelhante de renovação de um museu de história natural?

É necessário, antes de redigir o programa museológico, discutir profundamente sobre as escolhas fundamentais, no que diz respeito, primeiro, aos temas a tratar (e isto sem buscar a exaustividade mesmo em um museu nacional); segundo, os públicos-alvo; e, por fim, o estatuto dos objetos na cenografia (trata-se de elementos 
ilustrativos, quase objetos-pretexto, ou trata-se de elementos essenciais do discurso museal). Quando este programa museológico já estiver bem claro, cabe definir o programa arquitetural com os serviços e superfícies necessários aos objetivos - subdimensionar as reservas é tão perigoso quanto sobredimensionar os espaços de exposição, para a gestão futura da instituição - e as características técnicas necessárias à conservação dos espécimes expostos. É essencial que a realização arquitetural - quer se trate da reforma de um edifício ou da criação de um novo - esteja a serviço do projeto e que não seja apenas uma façanha arquitetural.

O senhor acredita que a apresentação museológica das ciências tem limites, já que afirmou antes que nem tudo é para ser exposto? Trata-se de que tipo de limite?

A encenação dos processos é difícil nas apresentações museográficas. O tempo relativamente breve das visitas, por exemplo, é incompatível com a apresentação dos processos evolutivos ou ecológicos, extremamente longos. Outros processos são invisíveis, no entanto a ciência contemporânea se interessa cada vez mais pela análise dos processos. Certamente convém tratar da evolução, da ecologia, da fisiologia, graças a suportes especiais (maquetes, vídeos, computadores, demonstrações, quando isto é possível), mas também convém inventar exposições modernas em torno de objetos e coleções científicas. Além do fato de que a realização de uma exposição é um processo relativamente longo, em contraposição à noção de atualidade e de descoberta veiculada instantaneamente pelas outras mídias.

Nos museus, museus no sentido pleno do termo, quer dizer: instituições onde existem coleções e uma atividade de pesquisa, é importante considerar que as exposições constituem apenas um dos elementos da política cultural da instituição. É particularmente fácil superar os limites da exposição, mencionados anteriormente, desenvolvendo outras atividades de mediação, pondo em evidência a diversidade das atividades do museu (leituras públicas, visita das reservas) e permitindo ações mais de acordo com a atualidade.

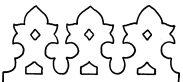




\section{Entrevista com Jean Davallon}

Jean Davallon é professor; diretor de pesquisas e responsável pela Escola Doutoral Espaço, Tempo e Poderes, Práticas Culturais, na Universidade de Avignon, onde desenvolve pesquisas sobre o patrimônio, as instituições culturais e os processos comunicacionais de produção e recepção de cultura. É membro do Laboratório Cultura e Comunicação, também na Universidade de Avignon, desenvolve uma abordagem sócio-semiótica dos fenômenos comunicacionais nos museus.

Há muitos anos o senhor vem refletindo sobre o funcionamento semiótico das exposições museais. Como definiria esta abordagem? Como evoluiu o seu pensamento?

O ponto de partida foi a análise semiótica da publicidade. Fiz minha primeira tese sobre a imagem e o texto no anúncio publicitário com Barthes. Mas em verdade, mais que a semiótica propriamente dita, procurava encontrar um modo, com as ferramentas semióticas, de analisar a maneira pela qual o funcionamento da linguagem do anúncio definia um lugar, uma posição para o leitor como sujeito social (como, por exemplo, a leitura do anúncio faz como se tivéssemos, antes, os valores atribuídos ao produto). Pode-se dizer, portanto, que desde o começo o que me interessava era compreender o funcionamento das imagens, dos textos etc, em situação social, ou, dizendo de outro modo: mais como mídias ou objetos culturais do que como simples processos semióticos. Portanto, uma abordagem sócio-semiótica, que se diria hoje pragmática.

É neste contexto que o estudo da exposição como mídia se interpôs: a hipótese era de que a exposição propusesse um dispositivo controlando a recepção do exposto (a leitura, se quisermos). Esta hipótese (que espero agora não ser mais apenas isso) é um fio condutor, que está ainda hoje no cerne de L'exposition a l'oeuvre, ${ }^{5}$ por exemplo; uma via que percorri e tornei a percorrer de várias maneiras. Deste ponto de vista, a exposição foi uma mídia excepcional, porque ela oferecia à análise, de maneira bem legível, a mensagem e o dispositivo da leitura. Muitas questões evidentemente mudaram ao longo do tempo. Há de fato uma evolução das teorias sobre as mídias e a linguagem, como por exemplo o desenvolvimento da abordagem pragmática.

Sem entrar em detalhe em discussões teóricas, esta abordagem permite sair da oposição entre o social e o semiótico, entre a análise sociológica (ou psicológica) da visita e dos visitantes, de um lado, e

\footnotetext{
5 Livro de autoria de Jean Davallon intitulado L'exposition a l'oeuvre: stratégies de communication et médiation symbolique (Paris, L'Harmattan, 2000).
} 
a análise puramente formal, ou semiótica, das exposições, de outro. Vamos nos interessar, por exemplo, pelo estatuto dos objetos do patrimônio, pelo modo segundo o qual a exposição (e o museu) constrói uma relação entre os visitantes e os objetos do patrimônio. Podem-se reexaminar noções como as de autenticidade, de testemunho, não no que diz respeito à qualidade intrinsecamente cabível aos objetos, mas no que diz respeito à relação social construída.

Paralelamente, há também a ampliação do 'olhar', partindo da exposição na direção do museu e do patrimônio. Neste momento, trabalho com este último conceito, após ter-me dedicado primeiro à linguagem das exposições e depois às enquetes junto aos visitantes. O que é interessante é que as questões que encontramos se aproximam daquelas identificadas pelos que trabalham sobre os empregos das mídias, tendo em vista os usos das novas tecnologias.

Como se pode explicar o surgimento da exposição como mídia, e qualé seu valor em relação às outras mídias, que atingem um número maior de pessoas (como a televisão, por exemplo)?

Hesito sempre em saber se, quando falamos de exposição como mídia, esta se desenvolve como uma mídia, ou se somos nós que construímos instrumentos de análise que permitem reconhecê-la como tal. Não há dúvida que a televisão, a imprensa, a publicidade são mídias no sentido tradicional, pois seu funcionamento se apóia sobre uma verdadeira economia industrial. Deste ponto de vista, a exposição se insere mais no âmbito do empreendimento cultural como a representação teatral, por exemplo - do que no âmbito da indústria cultural propriamente dita, como o cinema. Observe-se que a música reúne os dois âmbitos, com o concerto e o disco. Por um momento, poder-se-ia pensar que a edição eletrônica nos museus (sitesweb, cd-roms) permitiria aos mesmos, ao menos parcialmente, se ramificar na direção da indústria. Esta era, ao menos quando fizemos nossa enquete comparativa entre a França e o Canadá, uma idéia largamente presente entre profissionais e políticos. No momento, já não é assim. Em compensação, todos estes questionamentos e comparações, estes confrontos, fazem aparecer ainda mais claramente a particulariedade da mídia-exposição - se entendermos mídia como um dispositivo para a comunicação.

Desde o início me pareceu que a particularidade desta mídia era que ela fazia os visitantes se depararem fisicamente com os verdadeiros objetos, num espaço verdadeiro, embora tudo não passasse de um simples arranjo técnico, de modo a construir um mundo de linguagem.

Para responder à pergunta, pode-se comparar a dimensão pragmática da mídia-TV e da mídia-exposição. Pesquisadores se debruçaram sobre a maneira pela qual as informações na TV constroem uma relação com as notícias, de modo a fazer parecer que o que se 
vê é a realidade. O teatro, ao contrário, constrói uma relação de ficção - uma ficção compartilhada. A exposição constrói uma relação com os 'objetos verdadeiros', como diz Duncan Cameron, enfim, a exposição de museus grifo do entrevistador, que não é a mesma daquelas de parques temáticos de diversões. Foi me aprofundando neste sentido, que cheguei ao patrimônio: o objeto do patrimônio é, antes de mais nada, um objeto, cujo estatuto social de verdadeiro objeto permite remontar aos que foram os produtores, os proprietários etc. Daí vem a sua força simbólica.

Em um conferência no curso de Diploma de Estudos Aprofundados, em Paris, o senhor apresentou três museologias paradigmáticas: a do objeto, a do espetáculo e a das idéias. Podem-se utilizar estas categorias para analisar e reagrupar de outro modo os museus tradicionalmente classificados segundo a natureza de suas coleções e segundo os campos disciplinares aos quais estão ligados? Atualmente, quais são as diferenças mais importantes entre os museus de arte e os museus científicos?

Esta classificação concerne, de fato, essencialmente à mídiaexposição. Se é aplicável ao museu, é por repercussão. É certo que se pode classificar o Museu da Civilização, em Quebéc, de museologia do meio-ambiente, porque sua política é propor exposições desse tipo. Também é certo que as classificações por ciências de referência (arte, etnologia, história natural etc.) hoje são insuficientes.

Não sei como ocorre no Brasil, mas na Europa (e pelo que já disse, na América do Norte), são os chamados museus de sociedade, os ecomuseus, ${ }^{6}$ os que agora se renovam, que inovam, bem mais que os museus de arte e os museus de ciência, que fizeram parte das ondas precedentes de renovação. É em torno deles - aos quais é forçoso acrescentar os museus de pré-história e de arqueologia - que se colocam as questões mais vivas para a museologia, pois eles são também os que mais se relacionam com as questões sobre o patrimônio.

Que o senhor entende por democratização dos museus? Como o senhor vê os esforços para facilitar o acesso à cultura museal? As propostas da 'nova museologia', alimentadas desde a década de 1960, prosperaram?

É uma questão delicada, que implica a idéia que se faz da relação [desejável - inclusão do editor] com o museu. Simplificando: de um

\footnotetext{
6 O Movimento de Ecomuseu foi desenvolvido da década de 1970, inicialmente na França, por Georges Henri Rivières e Hugues de Varines. Os ecomuseus se fundamentam na idéia de territorialidade, considerando que a construção identitária a partir de uma comunidade ou território parte do reconhecimento ativo, pelos grupos envolvidos, de seu passado, sem a exclusão dos conflitos existentes, gerando uma atitude de apropriação ativa, reflexiva e incorporando as tradições, as mudanças e a reflexividade como contribuição para decidir o futuro. (N.E).
} 
lado, a democratização pode significar que todo mundo 'deve' vir ao museu (idéia que está subjacente a certas pesquisas de freqüência de público, onde se procura saber o percentual que vem ao museu, na intenção de aumentá-la); de outro lado, a democratização quer fazer do museu um ambiente cultural (idéia subjacente a muita renovação, como aquela do Louvre, por exemplo). Estas duas concepções são perfeitamente compatíveis, entretanto, seus fundamentos são diferentes. A primeira está mais voltada na direção do museu como ferramenta de educação, por onde todos devem passar (como a escola); a outra está voltada na direção do museu como espaço da atividade cultural (para apressar, mais numa lógica de saída cultural, que se escolhe ou não, que se aprecia ou não etc.).

Museus de vizinhança, ecomuseus, museus temáticos, museus comunitários, até onde se pode ampliar a idéia de museu?

É uma terceira via, aquela do museu como ferramenta, utensílio social. Este caminho está presente na 'nova museologia', mas ele efetivamente se desenvolveu com o redimensionamento do museu como depositário não somente do patrimônio, mas da memória. Daí a questão: até onde se pode estender esse conceito?

Devo dizer que tenho algumas restrições diante de qualquer forma de instrumentalização da memória. Mas esta é uma posição completamente oposta à de Henri-Pierre Jeudy, por exemplo, e largamente em desacordo com os diversos museus de memória da guerra, do holocausto etc.

Como o senhor vê o museu virtual? Qual é a sua especificidade em relação à experiência museal não virtual?

A resposta já está na pergunta: antes de mais nada, o que é um museu virtual? Uma cópia (ou um simulacro) do espaço de um museu real no qual se pode circular? Um catálogo on-line? Um banco de dados para consulta? A cada uma destas formas correspondem práticas e hábitos diversos. Em outras palavras, cada uma constitui uma oferta específica, diferente da outra, mas todas são diferentes de um museu real. A escrita da exposição não é a mesma, a localização física do espectador também não. E estar diante de um computador ou estar em um espaço público não é a mesma coisa. Enfim, o uso não é o mesmo, a experiência também não.

Então, o que se pode fazer com esta ferramenta, esta outra mídia? É preciso estudar o que já existe. Para isso, é preciso um verdadeiro programa de pesquisa, e não discursos de louvor ou de anátema; mas pesquisa de tese, por exemplo; e com relação à prática profissional, é preciso inventar. Propor não apenas objetos ou ferramentas, mas também formas de uso. 


\section{Entrevista com Daniel Jacobi}

Daniel Jacobi é professor de ciências da informação e da comunicação na Universidade de Avignon e membro do Laboratório Cultura e Comunicação, que desenvolve pesquisas sobre as diferentes formas de mediação da cultura e, em particular, dos patrimônios e dos museus. A princípio suas pesquisas focalizaram, no início da década de 1980, o domínio particular das formas lingüísticas e semióticas, da popularização da ciência no campo das ciências da vida e da saúde. A partir da década seguinte, começou a abordar igualmente os textos e os registros scriptovisuais nos museus e nas exposições. A comunicação científica e a educação não-formal constituem os dois eixos permanentes de seu trabalho.

Quais são os principais obstáculos e a limitação da dilvulgação das ciências nomomento?

Os obstáculos da popularização das ciências não são simples transtornos acidentais da comunicação. É a própria natureza dos conceitos e saberes científicos que torna difícil sua apropriação pelos leigos, não-especialistas. Compreender a ciência exige paciência e esforços da parte dos receptores. As ciências são diversificadas e complexas, utilizam modelos abstratos cada vez mais elaborados. Elas se se encontram muito distantes da percepção e rompem deliberadamente com o pensamento comum. A divulgação, qualquer que seja sua operacionalidade, não chega a superar facilmente esta característica intrínseca das ciências contemporâneas.

Como se articulam educação e divulgação das ciências? A alfabetização científicaéuma questão pertinente?

O espaço da educação e da formação básica é evidentemente uma prioridade em toda parte. É na escola que se transmitem a todas as crianças e aos jovens não apenas a cultura elementar, mas, sobretudo, o domínio dos recursos de aquisição autônoma de uma cultura complexa e ampla. E sem a escola nada se pode fazer. Portanto, nas sociedades desenvolvidas, o setor não formal (a educação informal), que engloba mídias, como os museus ou as associações beneficentes, ganha cada vez mais importância. Isto não só por causa do aumento dos períodos de lazer, mas também pela reinvidicação do acesso à cultura para todos e durante toda a vida. O fato de que, a partir de agora, este setor tenha se tornado, ao menos em parte, um espaço comercial (imprensa, cinema, televisão, aí incluída a Internet) não é estranho ao seu desenvolvimento espetacular e ambíguo.

Todavia, a despeito do aumento da oferta, não é certo que sejam os mais desprovidose aqueles que têm mais necessidade de cultura para se adaptar à sociedade os que usufruem mais do setor não formal. 
A divulgação científica nos museus propõe questões específicas em relação a outros espaços de divulgação das ciências?

No caso da mídia-exposição, os problemas relacionados à divulgação das ciências permanecem os mesmos. Contudo, esta mídia demanda esforços particulares ligados à sua natureza específica. Assinalemos algumas de suas exigências. A apresentação de teorias ou modelos em uma exposição nos obriga a conceber e fabricar unidades de exposição em três dimensões. Quer dizer: para materializar um conceito ou uma teoria sob a forma de um artefato ou de uma manipulação, deve-se fazer um trabalho complexo e bem feito de transposição museográfica. Por exemplo, como representar uma teoria tão complexa quanto a das placas tectônicas ou as leis da hereditariedade?

Em segundo lugar, recorrer ao visual e à imagem ${ }^{7}$ parece ser um registro oportuno. Mas a diversidade assim como a complexidade dos campos visuais tornam improvável a interpretação destas imagens pelos visitantes. Por não conhecer os códigos semióticos utilizados para fabricá-las, estas imagens permanecem não apenas polissêmicas, mas também enigmáticas e quase indecifráveis. Enfim, contrariamente a outras mídias de difusão ou de divulgação, os textos sofrem fortes restrições nas exposições. Os textos devem ser breves para não tomar todo o espaço e permanecer legíveis para visitantes em trânsito e freqüentemente distraídos. A relativa raridade dos textos e sua brevidade podem engendrar lapsos ou imprecisões de sentido difíceis de superar.

É possível, no século XXI, tornar a encontrar divulgadores científicos como Louis Figuier ou Camille Flammarion?

Louis Figuier e Camille Flammarion, dois dos maiores e mais renomados divulgadores científicos da segunda metade do século XIX, foram, ambos, cientistas. Louis Figuier renunciou à carreira científica para tornar-se escritor de ciências e sonhou por toda a vida em inventar um gênero novo: o teatro científico. Camille Flammarion, como autodidata, tornou-se um astrônomo quase profissional. Embora sem a formação acadêmica, foi reconhecido como especialista no assunto, pelo seu Tratado de Astronomia fartamente ilustrado.

Podemos considerar que certos cientistas, que interromperam a carreira de pesquisadores para tornarem-se uma espécie de profissionais da mídia, desempenham, em certa medida, um papel parecido hoje. Pensamos, na França, em personagens como Reeves, LeprinceRingue ou ainda Coppens. Atualmente, muitos pesquisadores e

$7 \mathrm{O}$ autor refere-se à imagerie, termo que designa os registros imagéticos de estruturas, fenômenos, processos estudados pelos cientistas. (N.E.) 
universitários publicam livros documentais 'semivulgarizados', por exemplo, em biologia, em medicina ou em física.

Como o senhor vê a idéia do 'terceiro homem' dentro do processo de dioulgação das ciências? Qualé o seu papel? Em que sentido ele se distingue de outros profissionais como, por exemplo, os cientistas?

A idéia do terceiro homem se impôs, na década de 1950, para concretizar a necessidade de um esforço, nas mídias, para colocar a ciência e a técnica ao alcance de um número maior de pessoas. A idéia do terceiro homem consiste em fazer intervir uma nova categoria de atores (jornalistas mediadores) na comunicação científica. Seu papel é otimizar a comunicação entre os especialistas e o público leigo, traduzindo o jargão dos especialistas para a linguagem corrente, falada por todos.

O paradigma do terceiro homem é relativamente ambíguo. De um lado, ele põe em foco um fenômeno importante: é preciso gerar a comunicação científica inventando modalidades de difusão adaptadas às expectativas do público e a suas representações. De outro, ele faz crer que a comunicação científica é complexa, difícil, e até impossível sem apelar para os profissionais mediadores, que impõem, de fato, suas regras de 'boa' comunicação.

Os mediadores que intervêm na difusão das ciências correspondem, hoje, a diferentes categorias profissionais: os especialistas das mídias, certamente, mas também o pessoal dos museus e até os docentes de ciências. Todavia, é evidente que os especialistas (pesquisadores e universitários, conservadores de museus etc) participam ativamente tanto da difusão como da midiatização dos saberes sábios, e isto por duas razões. A primeira é que a difusão faz parte de suas tarefas: fazer conhecer os resultados da pesquisa e divulgálos é um dever. A segunda razão é que o reconhecimento e a notoriedade são garantias de crédito e de meios suplementares, o que não deixa os especialistas indiferentes, é claro.

Certos divulgadores defendem o emprego da analogia e da metáfora nos textos de divulgação. Outros consideram esta prática perigosa, já que as figuras retóricas afastariam muito o tex to de seu objeto (científico) inicial. Como o senhor se posiciona diante desse emprego?

Antes de mais nada, lembremos que as figuras e expressões ditas metafóricas fazem parte de todas as línguas naturais e que o seu emprego não está de modo algum restrito às ciências. Todas as palavras na comunicação têm sentidos próprios e sentidos figurados. As figuras são um fator poderoso na evolução das línguas. O que é próprio das metáforas bem-sucedidas é que elas se fixam nas línguas e conferem novos e estáveis sentidos a certas palavras.

A comparação e a analogia, mais do que as figuras de retórica, como a metáfora ou a metonímia, correspondem a mecanismos ló- 
gicos destinados a fazer compreender e explicar. Certamente, a natureza do termo de comparação ou o tipo de analogia usado pode ser escolhido com mais ou menos cuidado e discernimento. Mas em si, estes procedimentos não são condenáveis, e os próprios cientistas não hesitam em utilizar modelos, como no caso das ciências da vida, que são em grande parte analógicos. Por exemplo: quando se escreve, para enfatizar sua importância, que a dor é um sinal de alarme, o que se faz é retomar uma teoria consensual na comunidade dos especialistas.

Os desenhos animados e as histórias em quadrinhos levam à divulgação científica?

Há muito tempo é sugerido que as mídias de comunicação mais populares e atraentes, como os quadrinhos, seriam suportes melhores de difusão para certas categorias de público. Mas será suficiente retranscrever em quadrinhos as teorias complexas para que elas apaixonem todos os jovens? E para convencê-los das precauções básicas a tomar face aos perigos da Aids, os quadrinhos serão os mais eficazes? Isto é, infelizmente, altamente improvável: a primeira qualidade de uma história em quadrinhos é sua própria natureza, quer dizer, uma autêntica figuração narrativa com personagens e histórias críveis.

Os leigos, atraídos pelos quadrinhos, percebem instantaneamente que a divulgação, pretensamente sob a forma de histórias em quadrinhos, copia desastradamente um gênero e se entediam rapidamente.

No artigo 'Sobre uma descoberta e três desenhos', o senhor mostra a importância das interpretações pessoais a propósito das imagens veiculadas nos artigos científicos. O senhor assinala, em particular, as interpretações diferentes em três artigos publicados pelo Paris Match, pelo L' Expresse por Ciência e Vida, a respeito da descoberta de restos humanos pré-históricos por exploradores austríacos. Na sua opinião, como a imagem pode contribuir para a divulgação das ciências? Como o senhor analisa a intervenção do staff profissional das mídias no processo de divulgação?

A criação de imagens e a busca de 'figurabilidade ${ }^{8}$ são duas dimensões extraordinariamente ricas da divulgação das ciências e das técnicas. Por um lado, os cientistas mesmos elaboram imagens refinadas e originais para construir suas experiências, para provar e argumentar. $\mathrm{O}$ conhecimento científico tanto é visual quanto

\footnotetext{
8 'Figurabilidade' é uma noção apresentada por Freud ao analisar os processos psíquicos que produzem o sonho. Consiste na operação de substituir textos por imagens ou 'figuras'. Esta operação equivale a um duplo processo de produção de imagens: um processo interno à linguagem de natureza sintática ou narrativa e um processo de transposição de um sistema semiótico (o discurso) a um outro (o visível). (N. E.)
} 
lingüístico. Mas, por outro, pode-se também tentar visualizar as teorias, os conceitos ou os modelos, por exemplo, com esquemas ou desenhos, e conferir, assim, sob forma sinótica e figurada, uma concretude mais ou menos realista e analógica a conceitos por natureza abstratos.

As imagens numéricas e as mediações instrumentais que tornam visível o infinitamente pequeno ou o infinitamente longe dotam as ciências de um repertório visual original. Estas figurações supõem o domínio de técnicas muito elaboradas. Do mesmo modo, as representações visuais desenhadas necessitam que se recorra a técnicos ou profissionais da imagem talentosos e às novas possibilidades que a infografia confere aos técnicos da semiologia gráfica. Evidentemente, elas não estão ao alcance de qualquer um. As revistas comerciais e os grandes editores dispõem de meios que hoje lhes permitem fazer um trabalho de qualidade, impossível para os amadores, dotados apenas de boa vontade. Portanto, é arriscado pensar que as imagens plásticas, não importando a sua qualidade, consigam comunicar de modo mais eficaz que as mensagens lingüísticas.

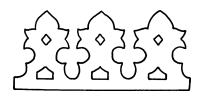

